\title{
Sleep in the crustacean crayfish
}

Fidel Ramón y Romero*

Universidad Nacional Autónoma de México, Faculty of Medicine, Department of Physiology, Mexico City, Mexico

\begin{abstract}
Sleep is defined as a state of unconsciousness, reduced locomotive activity and rapid awakening, and is well established in mammals, birds, reptiles and teleosts. Commonly, it is also defined with electrical records (electroencephalogram). which are only well established in mammals and to some extent in birds. However, sleep states similar to those of mammals, except for electrical criteria, appear to occur in some invertebrates. Currently, the most compelling evidence of sleep in invertebrates has been obtained in the crayfish. In mammals, sleep is characterized by a brain state that is different from that of wakefulness, which includes a change to slow waves that has not been observed in insects. Herein, we show that the crayfish enters a brain state with a high threshold to vibratory stimuli, accompanied by a form of slow wave activity in the brain, quite different from that of wakefulness. Therefore, the crayfish can enter a state of sleep that is comparabfe to that of mammals.
\end{abstract}

KEY WORDS: Sleep. Slow wave activity in the brain. Crustacean. Brain.

\section{Introduction}

The fact that humans and animals we usually come in contact with do sleep has been known since long time ago. Research has also been carried out in some invertebrate animals, although it has been of behavioral nature and not aimed at identifying the reason for sleep.

Kayser and Steiner-Kayser ${ }^{1,2}$ showed that, under certain conditions, bees lose muscle tone, drop the antennae and remain still, a behavior they interpreted as a state of sleep. In turn, Tobler investigated numerous invertebrate animals and described that they spent several hours of the day motionless; she explained that passiveness as the sleeping behavior. ${ }^{3-5}$ Moreover, in numerous investigations on the Drosophila fly, periods of immobility were also interpreted as equivalent to sleep. However, there is no evidence that these animals had the sleep characteristics clearly outlined by Hobson. ${ }^{6}$

Our working group was not particularly interested in sleep in the crayfish, but in brain's processing of sensory signals and their effect on behavior. For that investigation, a freshwater crustacean, the crayfish, was used because its size facilitates the implantation of electrodes onto its brain and the performance of etectrophysiological records while the animal seems- to live a more or less normal life.

Crayfishes were kept in aquariums with tap water from which chlorine was removed by strongly stiexing ("old water"), which appeared not to bother the crayfishes, which can remain for several months under these conditions, even if the water gets muddy with their excretions; the water was changed when the latter occurred. Occasionally, the water in the aquariums evaporated and the animals tended to lay on their side on the surface when only 5 to $7 \mathrm{~cm}$ of water wereft,
Correspondence:

*Fidel Ramón y Romero

E-mail: fidelrr@unam.mx
Date of reception: 25-03-2019

Date of acceptance: 27-03-2019

DOI: 10.24875/GMM.M20000338
Gac Med Mex. 2019;155:496-499

Contents available at PubMed

www.gacetamedicademexico.com

0016-3813/@ 2019 Academia Nacional de Medicina de México, A.C.. Published by Permanyer. This is an open access article under the CC BY-NC-ND license (http://creativecommons.org/licenses/by-nc-nd/4.0/). 


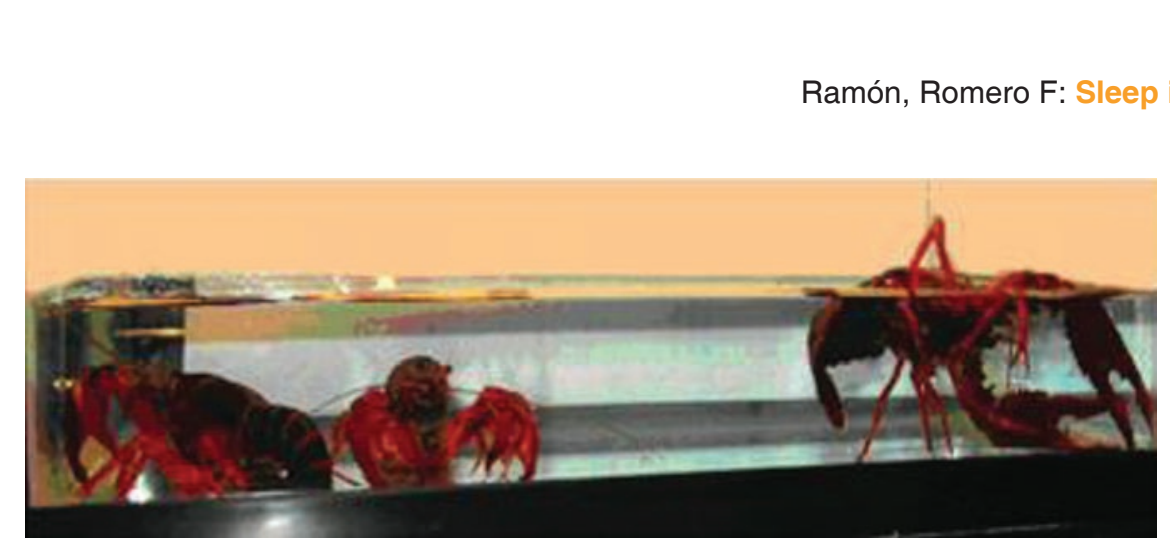

Figure 1. Crayfishes in a tank with vigorously agitated tap water and stored for later use. On the left, two crayfishes standing erected at the bottom of the aquarium. On the right, a crayfish lying in the water hanging on with its chelae. ${ }^{7}$

A

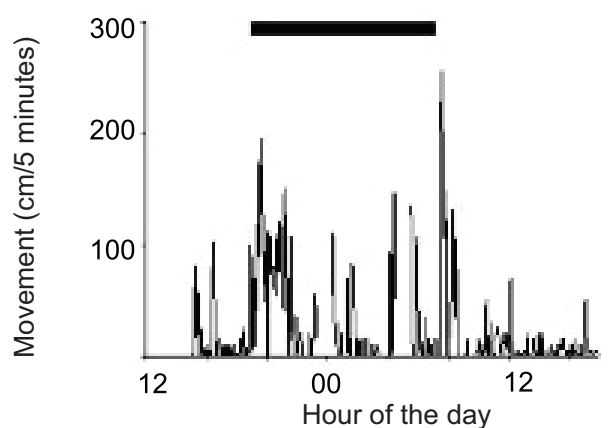

B
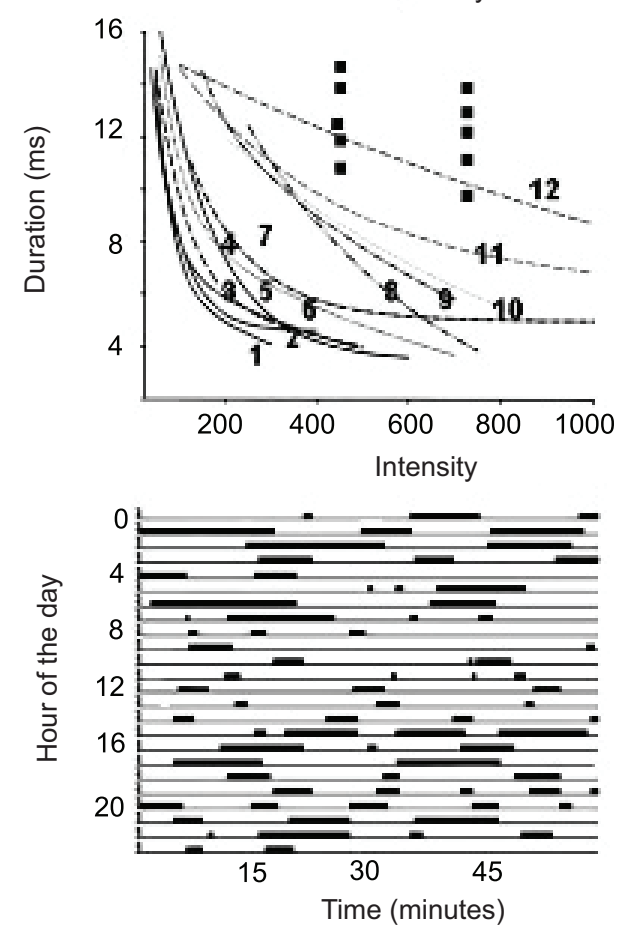

Figure 2. Records of a crayfish lying on the water surface. The black bar indicates the nocturnal period. A: Time during which the crayfish moves around the aquarium. Most movement corresponds to the hours around the light-dark and dark-light transitions; B: Intensityduration curves obtained by applying vibratory stimuli when the animal is moving (curves 1-7). Curves 1-10 correspond to stimuli applied to animals standing still (8-11) and curve 12, to an animal lying on water; C: Records of the period during which the crayfish is lying on the water. $A$ and $C$ show an example among 12 recorded cases. a behavior frequently observed by those who work with crayfishes (Fig. 1). Having no explanation for that position, we ventured several theories, including that they might be sleeping. However, that seemed so unlïkely that we abandoned the idea.

On one occasion, a crayfish with electrodes implänted onto the brain placed itself in that recumbent position; at that moment we thought it would be adequate to record its brain activity. Surprisingly, the oscilloscope records showed slow waves with a frequency of approximately $10 \mathrm{~Hz}$. Shortly after, the animaPregained its vertical position at the bottom of the aquarium and we observed the multitude of characteristic spikes of normal brain record. In view of this finding, we decided to wait for the crayfish to put itself of its side to obtain new records. We performed the corresponding tests on an animal while sleeping, to see if the pattern corresponded to that cerebral state (Fig.2).

\section{Signal analysis}

Initially, the records were analyzed using the fast Fourier transform to obtain frequencies, a strategy turned out not being the best for studying the encephalographic records, and thus using the wavelet transform was decided.

It should be remembered that the Fourier transform allows the analysis of a series of periodic signals, but only delivers a space of frequency and intensity. Gonversely, the wavelet transform provides a much more complete space, where intensity, frequency and time coincide, and hence it is more useful for identifying where and when frequency changes occur in the brain records.

\section{Sleep records}

The first indications of a change in the cerebral state of the crayfish were postural change and immobility as 

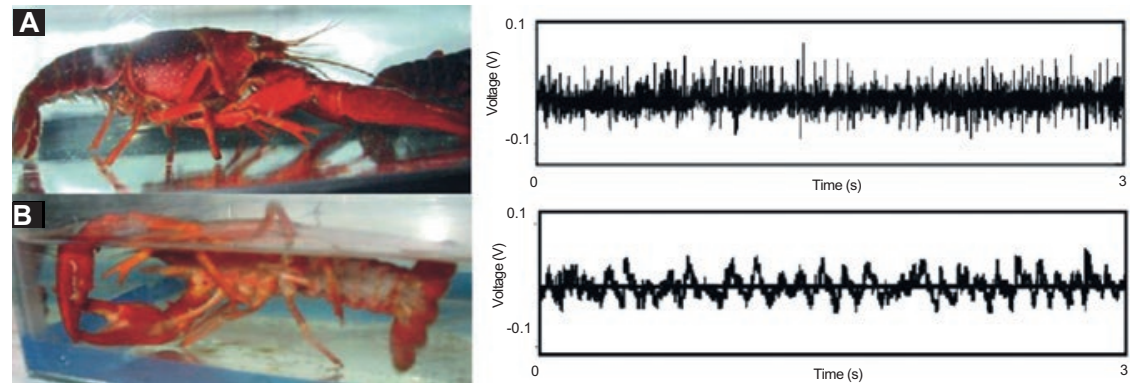

Figure 3. A: Photograph and electrophysiological record of a crayfish standing at the bottom of an aquarium. Note the spikes of up to $100-\mu \mathrm{V}$ amplitude, corresponding to the cerebral field record; B: Crayfish lying on its side on the surface of the water in an aquarium and record of Brain slow waves when the animal is in that position.?
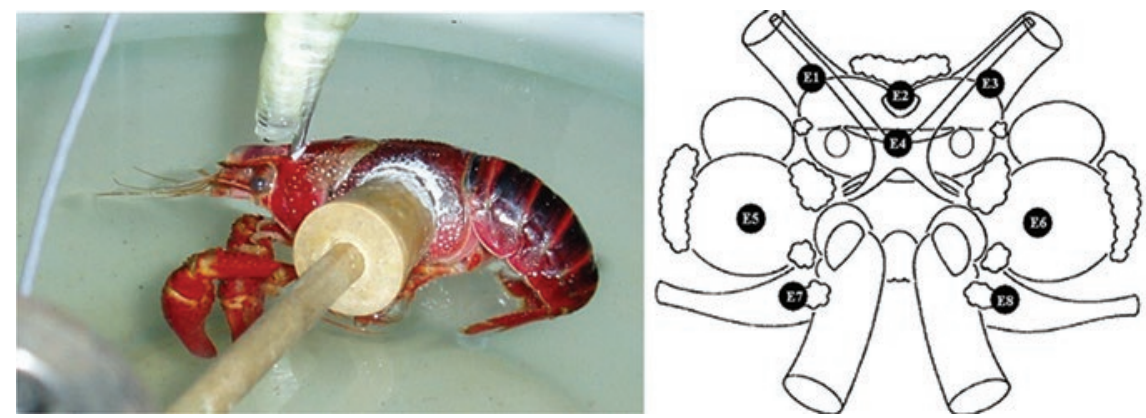

Figure 4. Crayfish suspended in the water in a position that allowed electrophysiological record of the brain, while the animal was free to $\bar{m}$ ove the appendices. The recorded cerebral regions are indicated in the brain diagram (with symmetric dark dots from 1 to 8): E1 and E3, lateral protocerebrum; E2, protocerebral bridge; E4, central brain complex; E5 and E6, deutocerebrum accessory lobe; E7 and E8, tritocerebrum (iimage taken from Mendoza-Angeles et al. $)^{8}$ The nomenclature is from Sandeman et al. ${ }^{9}$

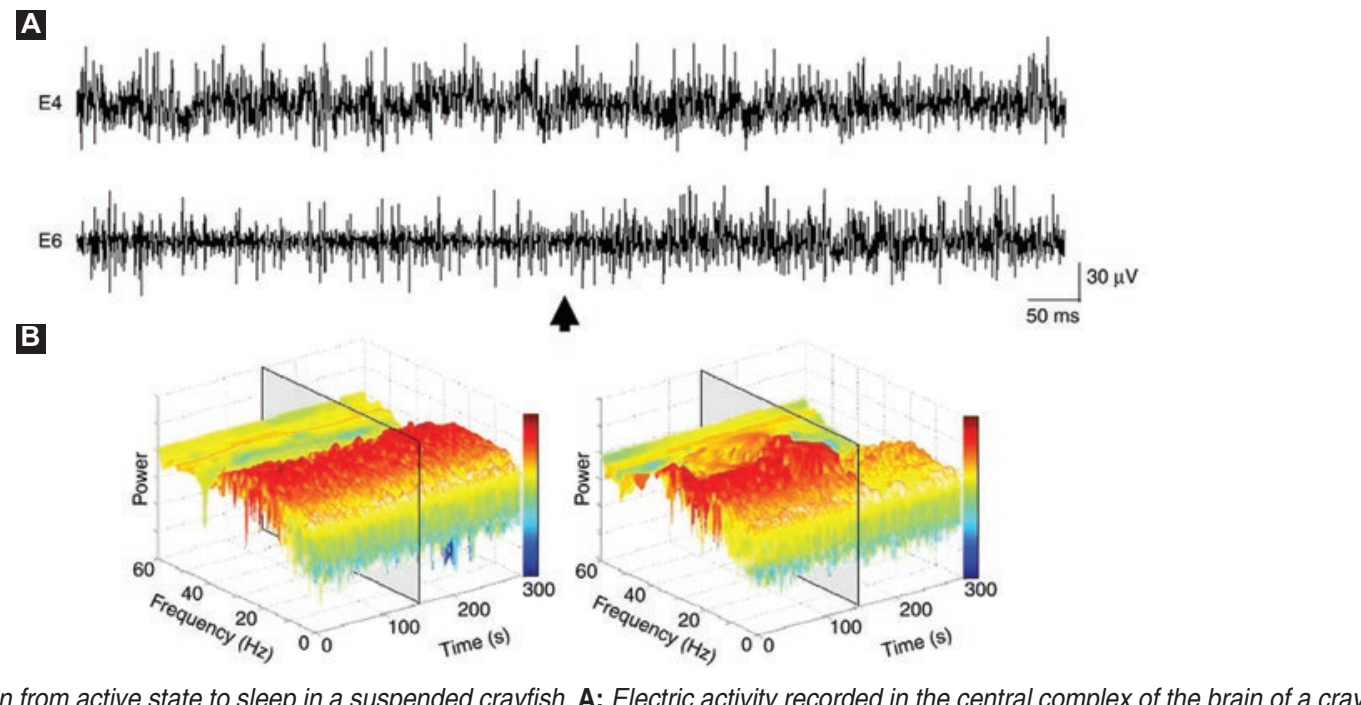

Figure 5. Transition from active state to sleep in a suspended crayfish. A: Electric activity recorded in the central complex of the brain of acrayfish (E4) and in the deutocerebrum (E6) during the transition from wakefulness to sleep; B: Analysis by wavelet transform of the records in E4 and E6 (the gray boxes indicate the moment of transition). Before the transition (marked by the arrow), there are no changes in E4 (recordand analysis by wavelet transform); conversely, in E6 there is a clear power decrease (gray box), corresponding to the appearance of slow waves and sleep onset (taken from Mendoza-Ángeles et al. ${ }^{10}$ ).

well as the change in the type of signals, which went from a continuous chain of spikes of between 20 and $50 \mu \mathrm{V}$ in amplitude to a series of slow waves of between 10 to $20 \mathrm{cps}$ (Fig. 3).
In a subsequent stage, the crayfish brain was mapped to locate the region that produces the stow waves. The crayfish was placed in a tank with water where it was fixed to a stem leaving all its appendages 
free. We made a hole in the cephalothorax to expose the dorsal and anterior surface of the brain, in order to enable choosing the region to be recorded (Fig. 4).

To compare the sleep records of the crayfish with those of other animals, including humans, it is necessary to take into account various factors. Humans have two types of sleep, one called REM (rapid eye movements) and another non-REM (without rapid eye movements) during which dreams occur. Although it is possible for the crayfish to move some of its appendages, it is not possible to determine if it does, and this model would therefore be only applicable to the nonREM sleep state.

In summary, as it can be clearly appreciated in Figure 5, the origin of the transition from an active crayfish to a sleeping one occurs with the change of a record dominated by spikes to one with slow waves, which occurs in the central brain complex. Meanwhile, other brain regions continue with records dominated by unitary spikes. The central complex of the crayfish is homologous with that of insects.

\section{Acknowledgements}

To engineer Karina Mendoza, for her collaboration with the programs to analyze the records by means of wavelet transform.

\section{References}

1. Kaiser W, Steiner-Kaiser J. Neuronal correlates of sleep, wakefuithess and arousal in a diurnal insect. Nature. 1983;301:707-709.

2. Kaiser W. Busy bees need rest, too. Behavioral and electromyographical sleep signs in honeybees. J Comp Physiol A. 1988;163:565-584.

3. Tobler I. Effect of forced locomotion on the rest-activity cycle of the cockroach. Behav Brain Res. 1983:8:351-360.

4. Tobler I, Stalder J. Rest in the scorpion. A sleep-like state? J_Comp Physiol A. 1988;163:227-235

5. Tobler I, Neuner-Jehle M. 24-h variation of vigilance in the cockroach Blaberus giganteus. J Sleep Res. 1992;1:231-239.

6. Hobson JA. Sleep is of the brain, by the brain and for the brain. Nature. 2005;437:1254-1256.

7. Ramón F, Hernández-Falcón J, Nguyen B, Bullock TH. Slow wave-sleep in crayfish. Proc Natl Acad Sci U S A. 2004;101:11857-11861.

8. Mendoza-Ángeles K, Hernández-Falcón J, Cabrera A, Ramón F. Črayfish brain states characterization with wavelet transform. $2^{\text {nd }}$ International Conference on Electrical and Electronics Engineering and XI Conference on Electrical Engineering, Mexico City, Mexico, September 7-9, 2005.

9. Sandeman D, Sandeman R, Derby C, Schmidt M. Morphology of the brain of crayfish, crabs, and spiny lobsters: a common nomenclature for homologous structures. Biol Bull. 1992;183:304-326.

10. Mendoza-Ángeles K, Hernández-Falcón J, Ramón F. Slow waves d̛uring sleep in crayfish. Origin and spread. J Exp Biol. 2010/213.2154-2164. 